\title{
ANALISA PERBANDINGAN METODE HISTOGRAM DAN MEDIAN FILTERING PADA CITRA MATA
}

\author{
Nissa Almira Mayangky ${ }^{1}$, Rousyati ${ }^{2}$, Dwiza Riana ${ }^{3}$, Sri Hadianti ${ }^{4}$, Ridan Nurfalah ${ }^{5}$, \\ Mochamad Rizky Kusumayudha ${ }^{6}$ \\ 1,2,3,4,5,6Universitas Nusa Mandiri \\ e-mail: nissa.nky@nusamandiri.ac.id, rousyati1@gmail.com,dwiza@nusamandiri.ac.id, \\ sri.shv@nusamandiri.ac.id, ridan.rlh@nusamandiri@ac.id, \\ mochammad.mox@nusamandiri.ac.id
}

\begin{abstract}
Abstrak
Metode biometrik seperti sistem pengenalan ekspresi wajah, finger print, sistem pengenalan mata merupakan sebuah teknologi terkemuka yang dapat dimanfaatkan sebagai otentikasi pengguna. Karena mempunya sifat unik dan stabil, maka dapat berfungsi sebagai identitas hidup. Biometri mata membantu dalam mengidentifikasi individu dengan cara yang lebih intuitif dan alami. Pengenalan mata berfokus pada mengenali identitas individu menggunakan karakteristik tekstur berdasarkan pola mata. Mata menjamin stabilitas jangka panjang dan persyaratan juga jarang untuk proses pendaftaran. Akurasi, isi informasi yang lebih tinggi, ketepatan waktu nyata, kinerja, stabilitas, pengelakan rendah dan keunikan menjadikan teknologi mata sebagai salah satu yang paling cocok untuk digunakan di bidang identifikasi. Citra mata yang berhasil didapatkan adalah citra mata yang terbagi menjadi data latih dan data uji, yang akan diolah pada tahap preprocessing. Pencahayaan, oklusi, jumlah piksel pada mata adalah elemen yang mempengaruhi kualitas citra. Penelitian ini berusaha untuk menyoroti kinerja berbagai teknik preprocessing digunakan dalam memperbaiki kualitas citra mata. Hasil dari penelitian ini menunjukan bahwa metode Histogram Equalization dapat memperbaiki citra lebih baik dibandingkan dengan metode Adaptive Histogram Equalization dan Median Filtering.
\end{abstract}

Kata Kunci: Biometrik, Mata, Preprocessing, Histogram Equalization

\begin{abstract}
Biometric methods such as facial expression recognition systems, finger prints, eye recognition systems are a leading technology that can be used as user authentication. Because it has a unique and stable nature, it can function as a living identity. Eye biometry helps in identifying individuals in a more intuitive and natural way. Eye recognition focuses on recognizing individual identities using texture characteristics based on eye patterns. Mata guarantees long term stability and requirements are also rare for the registration process. Accuracy, higher information content, real-time accuracy, performance, stability, low circumvention and uniqueness make eye technology one of the most suitable for use in the field of identification. The eye image that has been successfully obtained is the eye image which is divided into training data and test data, which will be processed at the preprocessing stage. Lighting, occlusion, number of pixels in the eye are elements that affect image quality. This study seeks to highlight the performance of various preprocessing techniques used in improving eye image quality. The results of this study indicate that the Histogram Equalization method can improve the image better than the Adaptive Histogram Equalization and Median Filtering methods.
\end{abstract}

Keywords: Biometric, Eye, Preprocessing, Histogram Equalization 


\section{Pendahuluan}

Manusia adalah individu dengan karakteristik pengenalan dan identifikasi menjadi pribadi. Dalam hal ini, pengenalan disebut pengenalan biometrik, yang merupakan karakteristik manusia yang dapat digunakan untuk membedakan satu orang dengan yang lain (Prihartono et al., 2011). Salah satu ciri atau organ manusia yang dapat digunakan untuk pengenalan adalah wajah. Tidak hanya wajah manusia, mata pula dapat digunakan untuk biometrik manusia. Semacam sidik jari, mata ialah bagian badan manusia yang bisa digunakan selaku pengenal seorang yang mempunyai tingkatan akurasi lumayan tinggi (Al Rivan \& Devella, 2020). Mata bersifat unik sehingga tiap orang mempunyai pola yang berbeda serta normal, sebab pada satu orang mempunyai tekstur mata berbeda antara kanan serta kiri. Apalagi pada orang kembarpun, mata berbeda pula (Tauvani, 2018). Karena itu, karakteristik mata menjadi salah satu karakteristik yang ditaruh pada KTP Elektronik serta diimplementasikan secara nasional. Pelaksanaan riset ini bertujuan buat memberbaiki mutu citra mata sehingga kedepan bisa mengidentifikasi seseorang melalui bentuk pola mata.

\section{Metode Penelitian}

Citra mata berisi komponen tertentu yang tidak diinginkan seperti bulu mata dan lainnya yang menurunkan kinerja proses pencocokan. Oleh karena itu, preprocessing merupakan langkah memproses bagian yang tidak relevan secara akurat dan penggalian wilayah mata efisien sehingga mendapatkan hasil yang diharapkan. Langkah preprocessing termasuk dalan ekstraksi filter untuk memperbaiki kualitas citra (Sutramiani et al., 2015). Preprocessing bisa dicapai dengan memakai metode- metode histogram equalization, adaptive histogram equalization dan median filtering. Untuk mendapatkan nilai perbandingan antara ketiga metode diperlukan teknik PSNR (Peak Signal to Noise Rasio) sehingga didapat jarak antar nilai dan MSE (Mean Square Eror) untuk melihat nilai eror terkecil.
A. Biometri

Dalam sistem biometrik umumnya digunakan model verifikasi serta identifikasi. Sistem verifikasi menyamakan biometrik seorang dengan satu biometrik acuan pada basisdata, yang diklaim kepunyaan orang tersebut. Sistem verifikasi menanggapi persoalan" apakah ini biometrik saya?". Pada sistem verifikasi cuma terjalin pencocokan satu ke satu. Sebaliknya sistem identifikasi menyamakan sesuatu biometrik dengan segala biometrik yang terdapat pada basisdata. Sistem identifikasi hendak menanggapi persoalan" kepunyaan siapakah biometrik ini?". Ada faktor pencarian pada sistem identifikasi sebab mengaitkan proses pencocokan satu ke banyak (Umam A Busro, Sunaryo, 2016)

B. Histogram Equalization

Metode histogram equalization sangat efektif digunakan tidak hanya untuk meningkatkan seluruh citra tetapi juga dalam meningkatkan detail tekstur. Ini juga memberi perubahan urutan tingkat warna abu-abu citra asli benar-benar terkendali. Oleh karena itu dapat meningkatkan citra lebih efektif (Ahmad \& Hadinegoro, 2012). Ini memungkinkan untuk daerah kontras lokal rendah untuk mendapatkan kontras yang lebih tinggi tanpa mempengaruhi kontras seluruhnya. Metode ini juga bekerja dengan baik untuk latar belakang dan foregrounds yang keduanya terang atau keduanya gelap (Ahmad \& Hadinegoro, 2012).

Metode histogram equalization sangat efektif tidak hanya dalam meningkatkan seluruh citra tetapi juga dalam meningkatkan detail tekstur. Ini memberikan perubahan urutan tingkat warna abu-abu citra asli benar-benar terkendali. Oleh karena itu dapat meningkatkan citra lebih efektif (Ahmad \& Hadinegoro, 2012). Pemerataan histogram adalah adalah teknik koreksi fitur yang dipelajari dan dipraktikkan dengan baik di bidang pemrosesan gambar untuk menormalkan karakteristik gambar digital suatu gambar, seperti kecerahan, skala dan kualitas gambar, skala abu-abu, dan kontras. Itu juga telah diperkenalkan ke dalam pemrosesan ucapan untuk menormalkan karakteristik ucapan dari ASR yang kuat, dan pendekatan yang baik telah berulang kali diusulkan dan dilaporkan dalam literatur. 
C. Adaptive Histogram Equalization Teknik ekualisasi histogram adaptif (Adaptive Histogram Equalization, AHE) pada prinsipnya sama dengan ekualisasi histogram. Nama lain dari AHE adalah local histogram processing, yaitu mengeksekusi proses ekualisasi histogram sebanyak beberapa kali masing-masing untuk setiap blok citra (subimage). Ukuran blok citra telah ditentukan berdasarkan kondisi citra atau kebutuhan penelitian yaitu antara lain $2 \times 2,4 \times 4,8 \times 8,16 \times 16$ piksel, atau ukuran yang lain (Hartono, 2014).

Kontras suatu citra ditentukan oleh rentang dinamisnya, yang didefinisikan sebagai rasio intensitas piksel paling terang hingga paling gelap. Histogram memberikan informasi tentang distribusi keseluruhan kontras dan intensitas dalam citra. Misalkan citra input $f(x, y)$ terdiri dari tingkat abu-abu diskrit dalam kisaran dinamis [0, L-1] maka fungsi transformasi C (rk) dapat didefinisikan sebagai persamaan :

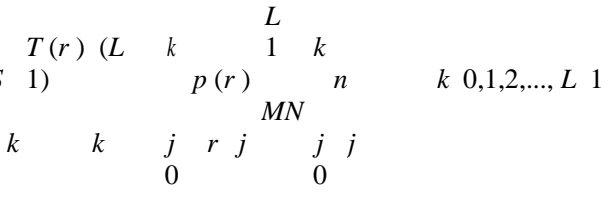

Persamaan transformasi histogram equalization pada citra digital, variabel $\mathrm{MxN}$ menunjukkan total jumlah piksel, L jumlah tingkat abu-abu, dan p r (rj) jumlah piksel dalam citra masukan dengan intensitas nilai rj. Rentang nilai input dan output abu-abu berada di kisaran $0,1,2, \ldots, \mathrm{L}-1$. Kemudian, transformasi histogram equalization memetakan input nilai rk (di mana $\mathrm{k}=0,1,2$, ...,L-1) hingga nilai output Sk (Pandey et al., 2016). Dapat dilihat pada Gambar 1 di bawah ini :

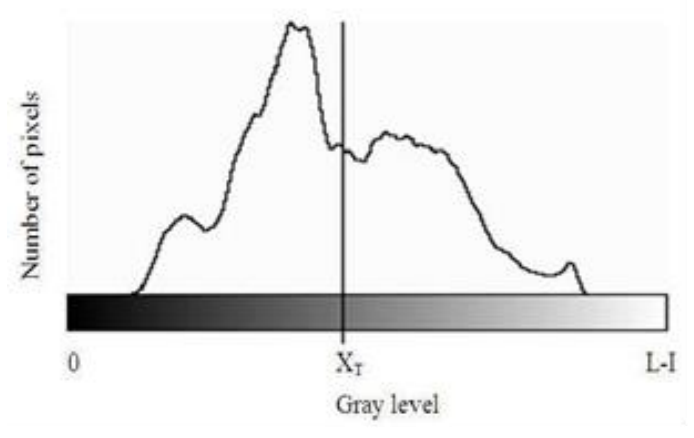

Gambar 1. Transformasi Histogram Equalization

Sumber : (Ahmad \& Hadinegoro, 2012)

\section{Median Filtering}

Median Filtering adalah filter statistik urutan yang paling terkenal. Filter median menggantikan nilai piksel dengan tingkat keabuan rata-rata dari piksel yang berdekatan (Sembiring, 2014). Median Filtering adalah filter non-linier yang dikembangkan oleh Tukey. Metode ini mengurangi noise dan menghaluskan gambar. Operasi pada filter ini dikatakan non-linier karena tidak termasuk dalam kategori operasi konvolusi. Operasi nonlinier dihitung dengan mengurutkan ulang nilai intensitas sekelompok piksel dan kemudian mengganti nilai piksel yang diproses dengan nilai tertentu. (Maulana \& Andono, 2018).

\section{Hasil dan Pembahasan}

Penilaian kualitas dalam tahap preprocessing dari pengenalan mata dilaksanakan dengan menggunakan metode Histogram Equalization, Adaptive Histogram Equalization, dan Median Fitering pada 44 citra yang bersumber dari database CASIA. Nilai-nilai PSNR yang diperoleh pada Tabel 1

Tabel 1. Hasil Perhitungan PSNR

\begin{tabular}{|c|c|c|c|}
\hline Gambar & $\begin{array}{c}\text { Histogran } \\
\text { Equalitatio } \\
\mathbf{n}\end{array}$ & $\begin{array}{c}\text { Adaptive } \\
\text { Histogran } \\
\text { Equalitation }\end{array}$ & $\begin{array}{l}\text { Median } \\
\text { Filtering }\end{array}$ \\
\hline Gambar 1 & 309915638 & 310759497 & 369362764 \\
\hline Gambar 2 & 344383398 & 331636419 & 379833553 \\
\hline Gambar 3 & 485938704 & 352706544 & 380504591 \\
\hline Gambar 4 & 404193771 & 336110579 & 380535619 \\
\hline Gambar 5 & 364838842 & 338209229 & 381560399 \\
\hline Gambar 6 & 449591408 & 346708054 & 381438091 \\
\hline Gambar 7 & 339691728 & 315055936 & 365356664 \\
\hline Gambar 8 & 379149885 & 316568505 & 367090862 \\
\hline Gambar 9 & 387517818 & 320415892 & 367508196 \\
\hline $\begin{array}{c}\text { Gambar } \\
10 \\
\end{array}$ & 402515904 & 317513764 & 359567775 \\
\hline ......................... & . & .............................. & ... \\
\hline …............. & . & ............................... & $\begin{array}{c}\text {...................... } \\
. . . \\
\end{array}$ \\
\hline $\begin{array}{c}\text { Gambar } \\
40\end{array}$ & 335071961 & 316423996 & 363257075 \\
\hline $\begin{array}{c}\text { Gambar } \\
41\end{array}$ & 584316649 & 323501842 & 364272573 \\
\hline $\begin{array}{c}\text { Gambar } \\
42\end{array}$ & 411753028 & 318825891 & 367746574 \\
\hline $\begin{array}{c}\text { Gambar } \\
43\end{array}$ & 435637276 & 340674507 & 383458754 \\
\hline $\begin{array}{c}\text { Gambar } \\
44 \\
\end{array}$ & 450391347 & 344348784 & 377509297 \\
\hline Total & 428038667 & 322917172 & 370393617 \\
\hline
\end{tabular}


Nilai MSE yang diperoleh dapat dilihat pada Tabel 2.

Tabel 2. Hasil Perhitungan MSE

\begin{tabular}{|c|c|c|c|}
\hline Gambar & $\begin{array}{l}\text { Histogran } \\
\text { Equalitati } \\
\text { on }\end{array}$ & $\begin{array}{c}\text { Adaptive } \\
\text { Histogran } \\
\text { Equalitation }\end{array}$ & $\begin{array}{l}\text { Median } \\
\text { Filtering }\end{array}$ \\
\hline Gambar 1 & 52,16 & 51,15 & 13,27 \\
\hline Gambar 2 & 23,59 & 31,63 & 10,43 \\
\hline Gambar 3 & 0,91 & 19,47 & 10,27 \\
\hline Gambar 4 & 5,95 & 28,53 & 10,26 \\
\hline Gambar 5 & 14,73 & 27,19 & 10,02 \\
\hline Gambar 6 & 2,09 & 22,36 & 10,05 \\
\hline Gambar 7 & 26,28 & 46,34 & 14,55 \\
\hline Gambar 8 & 10,59 & 44,75 & 13,98 \\
\hline Gambar 9 & 8,74 & 40,96 & 13,85 \\
\hline $\begin{array}{c}\text { Gambar } \\
10\end{array}$ & 6,18 & 43,79 & 16,63 \\
\hline $\begin{array}{c}\text {..................... } \\
\text {.... }\end{array}$ & 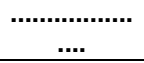 & ............................ & …............... \\
\hline …............... & …............... & .................... & c................. \\
\hline $\begin{array}{c}\text { Gambar } \\
40\end{array}$ & 29,23 & 44,9 & 15,27 \\
\hline $\begin{array}{c}\text { Gambar } \\
41\end{array}$ & 0,09 & 38,15 & 14,92 \\
\hline $\begin{array}{c}\text { Gambar } \\
42\end{array}$ & 5 & 42,48 & 13,77 \\
\hline $\begin{array}{c}\text { Gambar } \\
43\end{array}$ & 2,88 & 25,69 & 9,59 \\
\hline $\begin{array}{c}\text { Gambar } \\
44\end{array}$ & 2,05 & 23,6 & 11 \\
\hline Total & 12,75 & 40,72 & 13,14 \\
\hline
\end{tabular}

Mengingat tujuan akhir untuk mencapai hasil yang layak untuk evaluasi kualitas tahap preprocessing gambar mata, PSNR (Peak Signal To Noise Ration) nilai harus idealnya lebih besar dan terbalik dengan MSE (Mean Square Error). Dari hasil tes menunjukkan bahwa Histogram Equalitzation memberikan hasil yang terbaik. Kinerja algoritma dalam hal PSNR dan MSE telah diilustrasikan dalam gambar masing-masing.Dapat disimpulkan bahwa Histogram Equalitzation menghasilkan nilai PSNR maksimum dengan nilai MSE minimum pada Gambar 2.

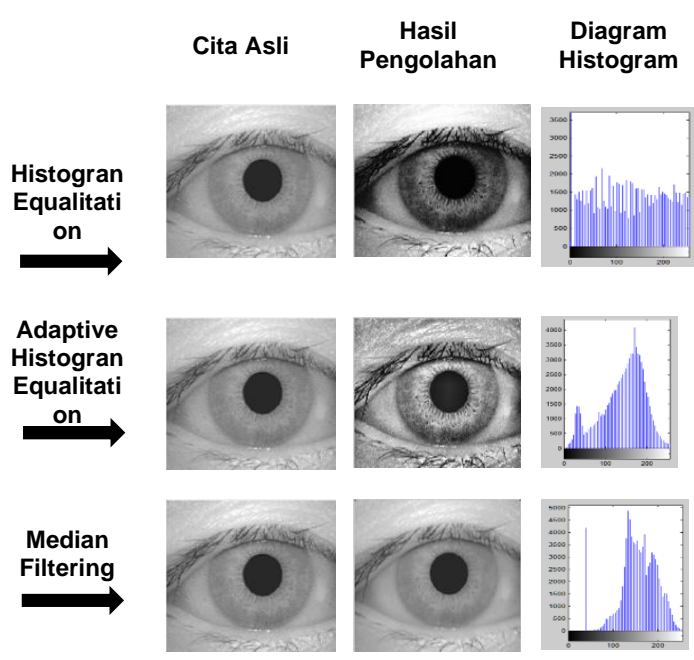

Gambar 2. Hasil Pengolahan Citra

Hasil rata-rata PSNR dapat dilihat pada Gambar 3.

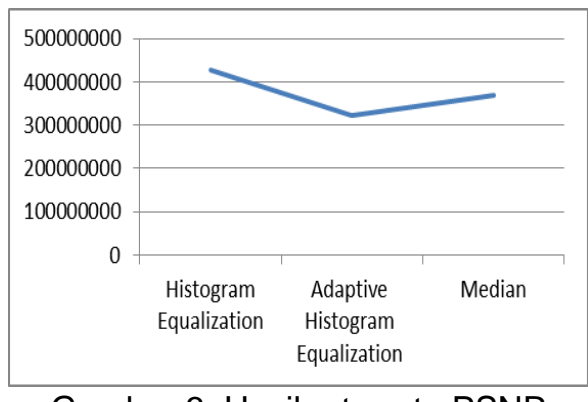

Gambar 3. Hasil rata-rata PSNR

Hasil rata-rata MSE dapat dilihat pada Gambar 4.

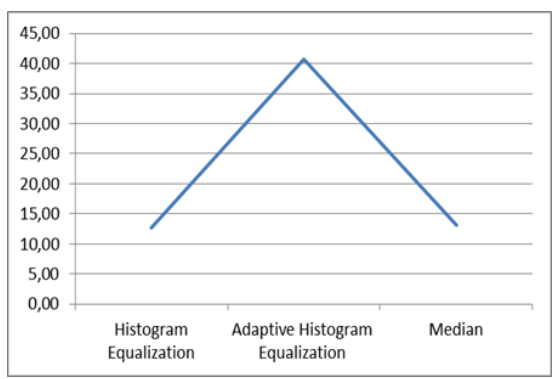

Gambar 4. Hasil rata-rata MSE

\section{Kesimpulan}

Metode biometrik mata terbukti menjadi salah satu metode terbaik yang digunakan dalam teknologi identifikasi. Penelitian ini mencoba membandingkan tiga metode peningkatan citra untuk meningkatkan kualitas citra mata. Teknik Histogram Equalitzation terbukti efektif dalam pra- 
pemrosesan langkah-langkah pengenalan mata dan lebih unggul dari Adaptive Histogram Equalization dan Median Filtering. Hasil penelitian ini dapat digunakan untuk pertimbangan dalam memilih metode untuk meningkatkan kualitas citra untuk preprocessing citra. Pengembangan selanjutnya dari hasil penelitian ini dapat diterapkan pada program aplikasi dengan prosedur pengenalan objek.

\section{Referensi}

Ahmad, N., \& Hadinegoro, A. (2012). Metode histogram equalization untuk perbaikan citra digital. Seminar Nasional Teknologi Informasi \& Komunikasi Terapan 2012 (Semantik 2012), 2012(Semantik), 439-445.

Al Rivan, M. E., \& Devella, S. (2020). Pengenalan Iris Menggunakan Fitur Local Binary Pattern Dan Rbf Classifier. Simetris: Jurnal Teknik Mesin, Elektro Dan IImu Komputer, 11(1), 97-106. https://doi.org/10.24176/simet.v11i1.3 717

Hartono, B. (2014). Analisa Teknik Adaptive Histogram Equalization dan Contrast Stretching untuk Perbaikan Kualitas Citra. Jurnal Teknologi Informasi, 19(1), 1-10.

Maulana, I., \& Andono, P. N. (2018). Analisa Perbandingan Adaptif Median Filter Dan Median Filter Dalam Reduksi Noise Salt \& Pepper. Cog/To Smart Journal, 2(2), 157. https://doi.org/10.31154/cogito.v2i2.26 .157-166

Pandey, M., Bhatia, M., \& Bansal, A. (2016). IRIS based human identification: Analogizing and exploiting PSNR and MSE techniques using MATLAB. 2016 1st International Conference on Innovation and Challenges in Cyber Security, ICICCS 2016, Iciccs, 231-235. https://doi.org/10.1109/ICICCS.2016.7 542309

Prihartono, T. D., Isnanto, R. R., \& Santoso, I. (2011). Identifikasi Iris Mata Menggunakan Alihragam Wavelet Haar. Transmisi, 13(2), 71-75-75. https://doi.org/10.12777/transmisi.13.2 $.71-75$

Sembiring, A. (2014). Perbandingan Algoritma Mean Filter , Median Filter dan Wiener Filter pada Aplikasi
Restorasi Citra RGB Terdegradasi Impulse Noise Menggunakan The Peak Signal To Noise Ratio ( PSNR ).

Sutramiani, N. P., Darmaputra, Ik. G., \& Sudarma, M. (2015). Local Adaptive Thresholding Pada Preprocessing Citra Lontar Aksara Bali. Majalah IImiah Teknologi Elektro, 14(1), 2730.

https://doi.org/10.24843/mite.2015.v14 i01p06

Tauvani, M. K. (2018). Pengembangan sistem identifikasi iris mata menggunakan metode wavelet haar. 2(1), 344-351.

Umam A Busro, Sunaryo, Y. erni. (2016). Implementasi Metode Anfis-Minkowski Untuk. 2(3). 